\title{
Intrastromal Corneal Ring Segments (ICRS) insertion in steep Versus Flat axis for treatment of keratoconus
}

\author{
H.A.Elgazzar ${ }^{1}$, M.R.Elsayed ${ }^{2}$, M.G.Sharawy ${ }^{3}$ and S.G.Mohammed ${ }^{4}$ \\ ${ }^{1}$ Professor \&Head of Ophthalmology Dept, Faculty of Medicine, Benha Univ., Benha, Egypt \\ ${ }^{2}$ Assistant professor of Ophthalmology Dept., Faculty of Medicine, Benha Univ., Benha, Egypt \\ ${ }^{3}$ Lecture of Ophthalmology, Faculty of Medicine Benha Univ., Benha, Egypt \\ ${ }^{4}$ (M.B.B.C.H) , Faculty of Medicine, Benha Univ., Benha, Egypt \\ E-Mail:sallyelgheriany@gmail.com
}

\begin{abstract}
Keratoconus is an ectatic disorder that manifests itself around puberty. Despite the different ways of management of keratoconus, its management is a continuous field of research. The aim of this study was assessment of the efficacy of the Intrastromal corneal ring segments (ICRS) insertion in Steep Versus Flat axis for treatment of keratoconus. The study is a prospective, non-randomized, interventional clinical study, included a total of 30 eyes of 24 patients. We insert ICRS In two different site of cornea in the steep meridian vs. flat meridian and follow-up $1 \mathrm{w}, 3 \mathrm{~m}$ and $6 \mathrm{~m}$. after surgery. this technique is statistically significant decreasing myopia, corneal steepness, and decentration of the of the corneal apex. The technique appears to be safe and is also potentially reversible. The corneal intrastromal implantation system provides a new option for keratoconus management.
\end{abstract}

\section{Introduction}

Keratoconus is a bilateral, corneal, ectatic, noninflammatory condition, the hallmark of which is progressive corneal steepening and thinning, which induces irregular astigmatism, myopia, and protrusion, leading to mild to marked impairment in the quality of vision and secondary loss of best-corrected visual acuity (BCVA) [1].

Over the last two decades, there has been a revolution in the knowledge related to the diagnosis and management of these conditions. In terms of diagnosis corneal topography has increased the ability of ophthalmologists to identify corneal ectasia at a much earlier stage than was previously possible [2].

Pentacam is a non-invasive system for measuring and characterizing the anterior segment using Scheimpflug photography. With this system a rotating Scheimpflug camera takes 100 images with 500 measurement points on the anterior and posterior corneal surfaces over a 180-degree rotation. The elevation data from all these images are combined to form a three-dimensional reconstruction of the corneal structure. After processing all this information, the internal software provides a large number of different calculations. It performs automatically the conversion of the corneal elevation profile into corneal wave front data [3].

Treatment for keratoconus include different procedures, such as rigid gas permeable contact lens wearing, thermokeratoplasty \& intrastromal corneal ring segment(s) (ICRS), corneal cross linking (CXL), therapeutic excimer laser treatments including phototherapeutic keratectomy and photorefractive keratectomy (PRK), and phakic intraocular lens or in combination have been proposed to delay or even prevent the need for corneal transplantation [4].

The insertion of intrastromal corneal ring segments (ICRS) is one of the treatment options that have been gaining popularity during the last decade. First evaluated as a treatment for mild to moderate myopia, these polymethyl methacrylate (PMMA) segments modify the corneal curvature by an arc shortening, flattening effect and have proven especially effective in reducing the irregular astigmatism caused by keratoconus [5].

Prior to implantation, a tunnel is created at a $70 \%$ $80 \%$ corneal depth, either by manual dissection, or with the femtosecond technology, the latter having a better safety accuracy profile [6].

Once inserted within the tunnel, the ICRS interacts with the corneal tissue and produces local flattening of the cornea. This flattening effect is believed to be related to both the geometrical properties of the ICRS (shape, arc length and thickness), and to its position relative to the corneal steep or flat axis [7].

Nomograms are proposed by the rings' manufacturer to help physicians in choosing the appropriate segment that would induce the desirable flattening effect. However, a lot of controversy remains concerning many technical issues like the incision sitewhether it should be performed over the steep versus the flat axis and like the number of rings to use and whether to insert superior rings or not [8].

The aim of this study was assessment of the efficacy of the Intrastromal corneal ring segments (ICRS) insertion in Steep Versus Flat axis for treatment of keratoconus.

\section{Patient and method}

The study included 30 eyes presenting with the diagnosis of keratoconus for ICRS implantation. Two groups created according to site of ICRS implantation (steep axis group, 15 eyes) and (Flat axis group, 15 eyes ). ICRS will be indicated because of existence of reduced best spectacle- corrected visual acuity (BSCVA) or contact lens intolerance. The patients included in the study must have keratoconus with mild to moderate degree of the disease \& clear optical 
zone and who are contact lens intolerant, with visual acuity less than 0.3 , kmax not less than $42 \mathrm{D}$ and not more than 65D and Patients must agree to undergo all clinical investigation plan require. Patients with central or para central scarring, opacity, or in the progressive phase of the disease, patients with kmax less than 42D and kmax more than $65 \mathrm{D}$, who has undergone previous intra-ocular or corneal surgery, or with active ocular disease other than keratoconus, or patients with previous hydrops, scarring and severe Keratoconus, or patients with systemic diseases that likely affects wound healing such as insulin dependent diabetes mellitus, patients with collagen vascular diseases, autoimmune diseases will be excluded from the study.

\subsection{Pre-operative evaluation}

- Visual acuity (uncorrected and best corrected visual acuity).

- Cycloplegic refraction.

- Slit lamp examination.

- Dilated fundus examination.

- K-readings and corneal thickness.

- Pentacam

In all cases antibiotic prophlyaxis consisting of topical ciprofloxacin was prescriped every eight Hours for two days before surgery. all procedures were performed under topical anaethesia and complete aseptic measures.

\subsection{Post-operative treatment}

The following was prescribed for all patients:

- Topical moxifloxacin hydrochloride $0.5 \%$ eye drops five times daily for one week.

- Topical fluoromethalone $0.1 \%$ eye drops four times daily for one week.

- Topical lubricant refresh liquigel four times daily for one month.

- Vitamin C sachets once daily for one month.

- Voltaren tablets for pain as needed for first two days after meals.

Postoperative visits were scheduled for the first postoperative day,3months and the 6 months. On the first postoperative day, UCVA measurement and slitlamp examination (intracorneal segment position and corneal integrity) were performed.

First week after surgery the treatment was adjusted $\&$ contact lens was removed. To assess the effect of femtosecond assisted intra corneal ring segment implantation in cases of keratoconus in the following:

- Uncorrected visual acuity (UCVA).

- Best corrected visual acuity (BCVA).

- Mean refractive astigmatism.

- Spherical equivalent.

- K- readings.

- Topographic cylinder.

- Corneal thickness at thinnest point.

- $\mathrm{Y}$ - orientation of thinnest point.

\section{Results}

In the present study, The age of the study population ranged from 20 to 47 years with mean age of $35.93 \pm 8.12$ years, Sixteen patients were males representing $53.3 \%$ of the study population, 14 were females representing $46.7 \%$ of the study population, 15 right eye representing $50 \%$ of the studied group while 15 left eye representing $50 \%$ of the studied group.

In the present study, The intrastromal tunnel for intra-corneal ring segments implantation was performed by means of the $150 \mathrm{kHz}$ femtosecond technology (WaveLight@ FS200 Femtosecond Laser).

In the present study the ICRS was inserted in the steep meridian in 15 eyes representing $50 \%$ of the studied group while inserted in the flat meridian in the other 15 eyes representing $50 \%$ of the studied group which represent novel technique.

In the present study procedure related complication include ring segment extrusion occurred in $6.7 \%$ of patients while Corneal neovascularization in $3.3 \%$, Corneal haziness in $3.3 \%$, Infectious keratitis in $3.3 \%$. ICRS decenetration in $3.3 \%$.Yellow white deposits in $3.3 \%$, Disc form keratitis in $3.3 \%$, Epithelial plug at the incision in $3.3 \%$.

Immediate post-operative keratometric changes In the steep group: shows the mean central corneal curvature (average $\mathrm{K}$ ) was reduced from $51.1 \pm 1.65$ to $47.47 \pm 1.74$ in the steep group with reduction about 3.6 $\mathrm{D}$ and that was stastically highly significant $\mathrm{P}$ value $(<0.001)$. k1 was reduced from $48.28 \pm 1.64$ to 46.22 \pm 2.91 About $2.06 \mathrm{D}$ and that was stastically significant $\mathrm{P}$ value (0.009) while $\mathrm{k} 2$ was reduced from $54.0 \pm 1.72$ to $49.31 \pm 1.93$ About 4.48 and that was stastically highly significant $\mathrm{P}$ value $(<0.001)$. The spherical equivalent is reduced from $5.87 \pm 0.76$ to $2.61 \pm 0.86$ about $3.16 \mathrm{D}$ that was stastically highly significant $\mathrm{P}$ value $(<0.001)$. The mean preoperative refractive astigmatism reduced $-5.35 \pm 0.97$ to $-1.82 \pm 0.96$ About 3.81 with stastically highly significant $P$ value $(<0.001)$ While topographic cylinder reduced from $5.69 \pm 0.8$ to $3.66 \pm 0.729$ about 2.11 that was stastically highly significant P value $(<0.001)$.

Immediate post-operative Refractive changes In the steep group: The mean preoperative UCVA improved from $0.097 \pm 0.035$ to $0.27 \pm 0.11$ was stastically highly significant $\mathrm{P}$ value $(<0.001)$. while the mean preoperative BCVA improved from $0.26 \pm$ 0.12 to $0.57 \pm 0.17$ with stastically highly significant $\mathrm{P}$ value $(<0.001)$. UCVA improved in $93.3 \%$, more than 2 lines gained in $60 \%$ of patients, While $26.6 \%$ gained 2 lines,6.6\% Gained 1 line and $6.6 \%$ not improved. BCVA improved in $93.3 \%$ of the studied group, $53.3 \%$ gained more than 2 lines, While $33.3 \%$ of patients Gained 2 lines and $6.6 \%$ of patient Gained 1 line, $6.6 \%$ of patients not changed,none patient were worsened.

Immediate post-operative keratometric changes In flat group:

shows that the average $\mathrm{K}$ in the Flat group was reduced from $51.88 \pm 1.81$ to $50.19 \pm 1.76$ about $1.83 \mathrm{P}$ 
value $(<0.001)$. The $\mathrm{k} 1$ was reduced from $49.12 \pm 1.9$ to $47.68 \pm 1.77$ about $0.57 \mathrm{P}$ value $(0.009)$ while The $\mathrm{k} 2$ was reduced from $54.83 \pm 1.76$ to $52.72 \pm 1.71$ about 2.16 and $\mathrm{P}$ value $(<0.001) . \mathrm{SE}$ is reduced from $5.76 \pm$ 0.84 to $4.21 \pm 1.02$ about $1.37 \mathrm{P}$ value $(<0.001)$. While topographic cylinder reduced from $5.74 \pm 1.07$ to $5.04 \pm 0.97$ about $0.08 \mathrm{P}$ value $(<0.001)$

Immediate post-operative Refractive changes In the Flat group: UCVA was improved in $53.3 \%$ of the studied group with None patients improved more than 2 lines in snellen chart for V.A of the studied group While $13.3 \%$ Gained 2 lines and $40 \%$ Gained 1 line. $26.6 \%$ of patients showed no improvement. while $20 \%$ patients were worsened.

BCVA in the flat group was improved in $66.6 \%$ of the studied group with none patients improved more than 2 lines, $13.3 \%$ patients gained 2 lines $53.3 \%$ Gained 1 line.20\% showed no improvement. While 13.3 were worsened

The Degree of improvement was better in the steep Fig(1)Vs The flat group Fig(2) so we changed the site of insertion in 9 patients from flat to steep who showed worsen or no improvments in $\mathrm{K}$ reading or refractive measurements Fig (3).

Post-operative keratometric changes after 6 Month These results after we change the site of

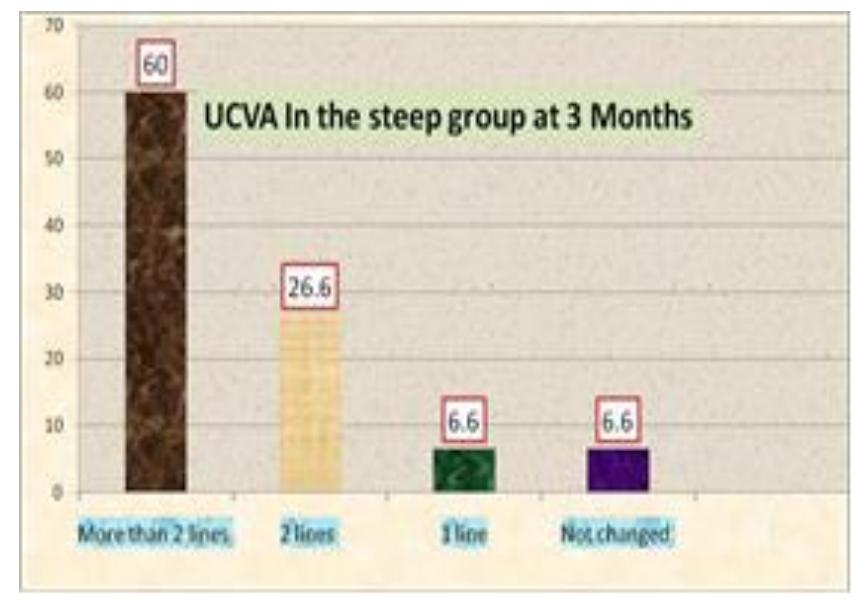

Fig (1) UCVA improved in the steep group insertion in 9 cases after 3 months from the flat axis to tradional site (steep meridian)axis, at 6 months follow up the mean central corneal curvature (average $\mathrm{K}$ ) was reduced from $51.49 \pm 1.75$ to $47.92 \pm 1.88$ with highly significant $\mathrm{P}$ value $(<0.001)$ so decrease keratometric reading by (3-5) diopeter. The k1 was reduced from $48.7 \pm 1.8$ to $46.28 \pm 2.42$ and that was stastically highly significant $\mathrm{P}$ value $(<0.001)$ while The $\mathrm{k} 2$ was reduced from $54.41 \pm 1.76$ to $49.87 \pm 2.13$ and that was stastically highly significant $P$ value $(<0.001)$. The preoperative spherical equivalent is reduced from $5.82 \pm 0.79$ to $2.72 \pm 0.99$ with significant $\mathrm{P}$ value $(<0.001)$.

Post operative Refracive changes after 6 Month Fig (4) These results after we change the site of insertion in 9 cases after 3 months from the flat axis to tradional site (steep meridian)axis. UCVA after 6 months improved in $90 \%$ of patients $50 \%$ gained more than 2 lines, 30\% Gained 2 lines, 10\% Gained 1 line, $10 \%$ showed no improvement. None patients were worsened at this group \& BCVA was improved in $93.3 \%$ of patients, $30 \%$ gained more than 2 lines, $53.3 \%$ Gained 2 lines and 10\%patients Gained 1 line, $6.6 \%$ showed no improvement. None patients were worsened at this group of patients.

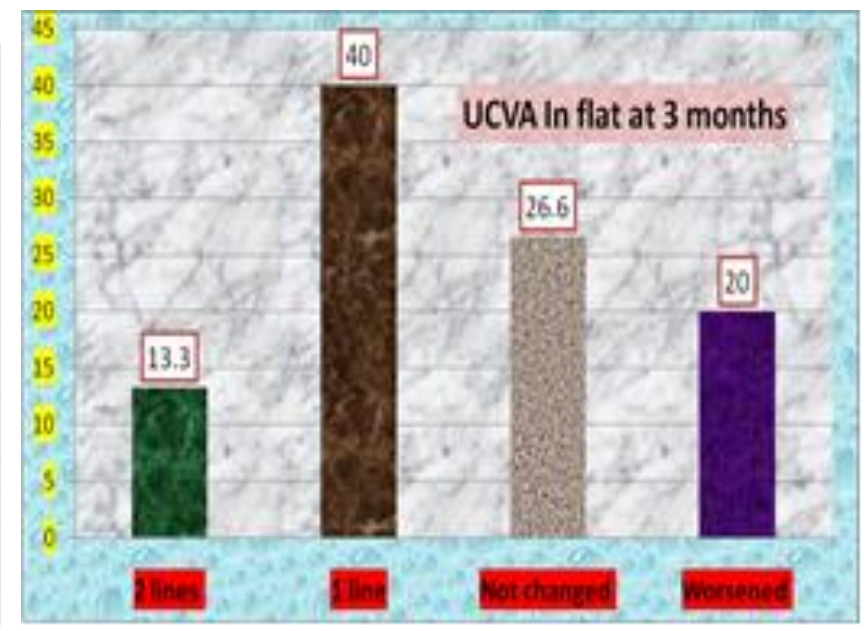

Fig (2) UCVA improved in the Flat group

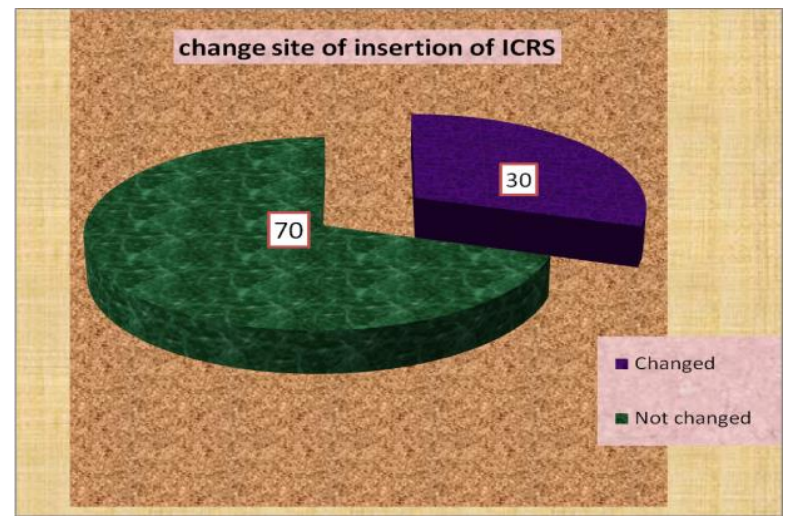

Fig (3) Change site of insertion 
Table (1) post-operative data at changed group at 6 Month.

\begin{tabular}{lcccc}
\hline Changed group (9) & $\begin{array}{c}\mathbf{3} \mathbf{~ m} \\
\text { Mean } \pm \text { SD }\end{array}$ & $\begin{array}{c}\mathbf{6} \mathbf{~ m} \\
\text { Mean } \pm \text { SD }\end{array}$ & Paired t test & P value \\
\hline k1 & $47.94 \pm 2.19$ & $45.71 \pm 2.2$ & 13.2 & $<0.001^{* *}$ \\
k2 & $49.19 \pm 1.75$ & $49.19 \pm 1.75$ & 16.66 & $<0.001^{* *}$ \\
KM & $50.47 \pm 2.03$ & $47.45 \pm 1.94$ & 15.5 & $<0.001^{* *}$ \\
Topographic cylinder & $5.05 \pm 0.62$ & $3.48 \pm 0.85$ & 15.88 & $<0.001^{* *}$ \\
UCVA & $0.13 \pm 0.04$ & $0.26 \pm 0.13$ & 3.62 & $0.007^{* *}$ \\
BCVA & $0.33 \pm 0.12$ & $0.58 \pm 0.12$ & 9.63 & $<0.001^{* *}$ \\
Refraction & & $-4.19 \pm 0.92$ & & \\
Sphere & $-2.44 \pm 0.58$ & $-1.39 \pm 0.52$ & 6.19 & $<0.001^{* *}$ \\
Cylinder & $-4.19 \pm 0.92$ & $-1.72 \pm 0.46$ & 12.52 & $<0.001^{* *}$ \\
Pre seq & $4.54 \pm 0.83$ & $2.23 \pm 0.59$ & 11.28 & $<0.001^{* *}$ \\
Pachy apex & $423.89 \pm 14.77$ & $423.89 \pm 14.77$ & - & - \\
Thinnest location & $412.78 \pm 14.7$ & $423.22 \pm 15.75$ & 10.29 & $<0.001^{* *}$ \\
y-orientation & $-0.51 \pm 0.08$ & $-0.31 \pm 0.09$ & 5.2 & $0.001^{* *}$ \\
\hline
\end{tabular}

Table (2) post operative data at All studied at 6 Month.

\begin{tabular}{lcccc}
\hline All study group (30) & $\begin{array}{c}\text { Pre operative } \\
\text { Mean } \pm \text { SD }\end{array}$ & $\begin{array}{c}\text { 6 months } \\
\text { Mean } \pm \text { SD }\end{array}$ & Paired t test & P value \\
\hline k1 & $48.7 \pm 1.8$ & $46.28 \pm 2.42$ & 7.02 & $<0.001^{* *}$ \\
k2 & $54.41 \pm 1.76$ & $49.87 \pm 2.13$ & 30.81 & $<0.001^{* *}$ \\
KM & $51.49 \pm 1.75$ & $47.92 \pm 1.88$ & 29.49 & $<0.001^{* *}$ \\
Topographic cylinder & $5.72 \pm 0.93$ & $3.88 \pm 1.07$ & 20.28 & $<0.001^{* *}$ \\
UCVA & $0.096 \pm 0.035$ & $0.25 \pm 0.12$ & 8.77 & $<0.001^{* *}$ \\
BCVA & $0.25 \pm 0.11$ & $0.54 \pm 0.16$ & 16.31 & $<0.001^{* *}$ \\
Sphere & $-2.82 \pm 1.64$ & $-1.93 \pm 1.24$ & 2.49 & $0.019^{*}$ \\
Cylinder & $-5.28 \pm 0.93$ & $-2.04 \pm 0.88$ & 20.75 & $<0.001^{* *}$ \\
Seq & $5.82 \pm 0.79$ & $2.72 \pm 0.99$ & 30.19 & $<0.001^{* *}$ \\
Pachy apex & $416.33 \pm 12.72$ & $421.07 \pm 12.74$ & 37.49 & $<0.001^{* *}$ \\
Thinnest location & $400.43 \pm 12.93$ & $419.1 \pm 13.78$ & 46.76 & $<0.001^{* *}$ \\
y-orientation & $-0.716 \pm 0.078$ & $-0.34 \pm 0.09$ & 39.9 & $<0.001^{* *}$ \\
\hline
\end{tabular}

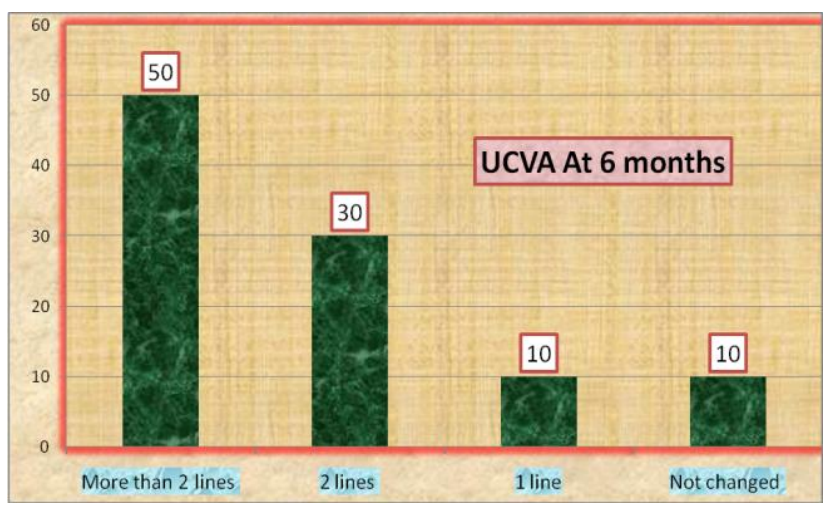

Fig (4) UCVAimprovement in total group at 6 Months

\section{Discussion}

This is a single center, The study was retrospective, non-randomized, interventional clinical study, included a total of 30 eyes of 24 patients with keratoconus diagnosed according to the standard criteria. Diagnosis was based on slit-lamp observation and corneal topography.

In the present study, The age of the study population ranged from 20 to 47 years with mean age of
$35.93 \pm 8.12$ years, Sixteen patients were males representing $53.3 \%$ of the study population, 14 were females representing $46.7 \%$ of the study population, 15 right eye representing $50 \%$ of the studied group while 15 left eye representing $50 \%$ of the studied group

A similar population were studied by [9]. Who Studied 40 eyes of 31 patients (19 men, 12 women) with a mean age of 38 years.

However [10] Studied bigger group with total of 611 consecutive keratoconic eyes of 357 patients 
treated with ICRS implantation; 213 were male and 144 were female, ranging in age from 10 to 73 years (mean age: 35.15 years). In comparison to [11] who studied ICRS in pediatric Fourteen eyes of 14 patients, with a mean age of 15.36 years (range $10-18$ years).

The present study The intrastromal tunnel for intracorneal ring segments implantation was performed by means of the $150 \mathrm{kHz}$ femtosecond technology (WaveLight@ FS200 Femtosecond Laser).

A similar population were studied by [12] who used the same femto second technology (WaveLight $\AA$ FS200 Femtosecond Laser).

And concordnat with [13] used the same technology on 56 eyes with keartoconus using Femtosecond Laser.But Discordant with [14] who Compare the surgical vs Femtosecond Laser in insertion of the ICRS in patients with Keartoconus And discordant with [15] who use the tradiotional surgical technique in insertion of the ICRS in patients with Keartoconus.

And also discordant with [16] Who insert ICRS By surgical technique in patients with Keartoconus \& keratoectasia.

In the present study the ICRS was inserted in the steep meridian in 15 eyes representing $50 \%$ of the studied group while inserted in the flat meridian in the other 15 eyes representing $50 \%$ of the studied group which represent novel technique.

These data discordant with [11] who insert ICRS in the steep meridian axis.And also discordant with [13] who insert ICRS in the steep meridian axis also.

In the present study procedure related complication include ring segment extrusion occurred in $6.7 \%$ of patients while Corneal neovascularization in $3.3 \%$, Corneal haziness in $3.3 \%$, Infectious keratitis in $3.3 \%$. ICRS decenetration in $3.3 \%$.Yellow white deposits in $3.3 \%$, Disc form keratitis in $3.3 \%$, Epithelial plug at the incision in $3.3 \%$.These results are in agreement with El Araby et al [17] who found ring extrusion in $(12.0 \%)$, ring decentration in $(4.0 \%)$ and infectious keratitis in one case $(4.0 \%)$.

And disagree with [18] who reported $0 \%$ Complication in his study on 15 eyes of 15 patients with the same device (Kera ring) ICRS.This can be explained by different site of insertion as in our study in the flat group the majority of complications $16.7 \%$ Vs 3.7 in the steep group.

Our result shows the mean central corneal curvature (average $\mathrm{K}$ ) was reduced from $51.1 \pm 1.65$ to $47.47 \pm 1.74$ in the steep group with reduction about 3.6 $\mathrm{D}$ and that was stastically highly significant $\mathrm{P}$ value (<0.001). k1 was reduced from $48.28 \pm 1.64$ to 46.22 \pm 2.91 About $2.06 \mathrm{D}$ and that was stastically significant $\mathrm{P}$ value (0.009) while $\mathrm{k} 2$ was reduced from 54.0 \pm 1.72 to $49.31 \pm 1.93$ About 4.48 and that was stastically highly significant $\mathrm{P}$ value $(<0.001)$. The spherical equivalent is reduced from $5.87 \pm 0.76$ to $2.61 \pm 0.86$ about $3.16 \mathrm{D}$ that was stastically highly significant $\mathrm{P}$ value $(<0.001)$. The mean preoperative refractive astigmatism reduced $-5.35 \pm 0.97$ to $-1.82 \pm 0.96$
About 3.81 with stastically highly significant $P$ value $(<0.001)$ While topographic cylinder reduced from $5.69 \pm 0.8$ to $3.66 \pm 0.729$ about 2.11 that was stastically highly significant $\mathrm{P}$ value $(<0.001)$.

These results in agree with (18) significant improvement in spherical equivalent refractive error from $-5.46 \pm 1.52$ diopters (D) preoperatively to $-2.01 \pm 1.63(P<0.001)$ postoperatively. The mean $K$ readings improved in the same period, from $48.11 \pm$ $1.95 \mathrm{D}$ to $43.31 \pm 2.31(P<0.001)$.

Our result, (5),Figure(28), Figure (29): The mean preoperative UCVA improved from $0.097 \pm 0.035$ to $0.27 \pm 0.11$ was stastically highly significant $P$ value $(<0.001)$. while the mean preoperative BCVA improved from $0.26 \pm 0.12$ to $0.57 \pm 0.17$ with stastically highly significant $\mathrm{P}$ value $(<0.001)$. UCVA improved in $93.3 \%$, more than 2 lines gained in $60 \%$ of patients, While $26.6 \%$ gained 2 lines, $6.6 \%$ Gained 1 line and $6.6 \%$ not changed.BCVA improved in $93.3 \%$ of the studied group, $53.3 \%$ gained more than 2 lines, While $33.3 \%$ of patients Gained 2 lines and $6.6 \%$ of patient Gained 1 line, $6.6 \%$ of patients not changed.

These results in agree with (11), Baseline average UCVA and BCVA were $0.07 \pm 0.09$ and $0.34 \pm 0.21$, respectively, and they improved to $0.25 \pm 0.15$ and $0.54 \pm 0.17$ after ICRS implantation $(p<0.01)$.

These results in agree with (18), The mean UCVA improved significantly from $0.79 \pm 0.48$ to $0.28 \pm 0.15$ $\operatorname{logMAR}(P=0.001)$. The mean preoperative BCVA was $0.36 \pm 0.21$ improved to $0.18 \pm 0.91 \log \mathrm{MAR}(P=$ $0.009)$

Our result shows that the average $\mathrm{K}$ in the Flat group was reduced from $51.88 \pm 1.81$ to $50.19 \pm 1.76$ about $1.83 \mathrm{P}$ value $(<0.001)$. The $\mathrm{k} 1$ was reduced from $49.12 \pm 1.9$ to $47.68 \pm 1.77$ about $0.57 \mathrm{P}$ value $(0.009)$ while The $\mathrm{k} 2$ was reduced from $54.83 \pm 1.76$ to 52.72 \pm 1.71 about 2.16 and $P$ value $(<0.001)$. SE is reduced from $5.76 \pm 0.84$ to $4.21 \pm 1.02$ about $1.37 \mathrm{P}$ value $(<0.001)$. While topographic cylinder reduced from $5.74 \pm 1.07$ to $5.04 \pm 0.97$ about $0.08 \mathrm{P}$ value $(<0.001)$.

These results disagree with (12), K1 decrease 3.26 $\mathrm{D}, P$ value $0.02, \mathrm{~K} 2$ decrease $3.01 \mathrm{D}, P \leq 0.01$, mean $\mathrm{K}$ decrease $3.24 \mathrm{D}, P$ value $(\leq 0.01)$. That could be explained by small number of patients $\&$ different site of insertion.

UCVA in flat group was improved in $53.3 \%$ of the studied group with None patients improved more than 2 lines in snellen chart for V.A of the studied group While $13.3 \%$ Gained 2 lines and $40 \%$ Gained 1 line. $26.6 \%$ of patients showed no improvement. while $20 \%$ patients were worsened.

These results disagree with (12) who use different devices there was improvement in total of $82.8 \%$ of patients, $36.3 \%$ of patients gained more than two lines of CDVA, while $10 \%$ of patient gained two line, and $36.5 \%$ Gained 1 line. $17.2 \%$ of patients showed no improvement.

That could be explained by different device and different site of insertion as in this group of patient we 
insert (Kerraring) in the flat meridian axis against all studies as de novel technique

These results after we change the site of insertion in 9 cases after 3 months from the flat axis to tradional site (steep meridian)axis, at 6 months follow up the mean central corneal curvature (average $\mathrm{K}$ ) was reduced from $51.49 \pm 1.75$ to $47.92 \pm 1.88$ with highly significant $\mathrm{P}$ value $(<0.001)$ so decrease keratometric reading by (3-5) diopeter. The $\mathrm{k} 1$ was reduced from $48.7 \pm 1.8$ to $46.28 \pm 2.42$ and that was stastically highly significant $\mathrm{P}$ value $(<0.001)$ while The $\mathrm{k} 2$ was reduced from $54.41 \pm 1.76$ to $49.87 \pm 2.13$ and that was stastically highly significant $\mathrm{P}$ value $(<0.001)$. The preoperative spherical equivalent is reduced from $5.82 \pm 0.79$ to $2.72 \pm 0.99$ with significant $P$ value $(<0.001)$.

These results agree with [19] who studied Thirtyfive eyes of 28 patients. Corneal topography showed corneal flattening in all eyes. The mean minimum $\mathrm{K}$ value decreased from $48.99 \mathrm{D}$ preoperatively to 44.45 $\mathrm{D}$ postoperatively and the mean maximum $\mathrm{K}$ value, from $54.07 \mathrm{D}$ to $48.09 \mathrm{D}$, respectively the decreases were statistically significant ( $P$ value $<0.001)$.

These results agree with [11] who studied ICRS In pediatric Fourteen eyes of 14 patients at 6 months follow up found that $\mathrm{K}$ minimum $(\mathrm{K}$ min) decreased from $48.9 \pm 3.25$ to $45.29 \pm 3.45 \mathrm{D}(p=0.001)$ and $\mathrm{K}$ maximum ( $\mathrm{K} \max )$ reduced from $55.92 \pm 4.56$ to 51.4 $\pm 3.33 \mathrm{D}(p=0.002) 6-12$ months after surgery.

But disagree with [15] who studied Intacs ICRS treatment of Keratoconus implantation Six months postoperatively in a prospective study and the mean keratometry value decreased just ( $0.75 \mathrm{~d}$ ).

That could be explained that they use another device (Intacs) in

And also disagree with [20] also using the same device (keraRing) but with surgical technique. As regard to corneal curvature, there was significant decrease of $\mathrm{K} 1, \mathrm{~K} 2$ and $\mathrm{Km}$ postoperatively, compared to corresponding preoperative values $(46.52 \pm 4.15,49.94 \pm 5.96, \quad$ and $48.23 \pm 4.85$ vs $48.67 \pm 4.46,54.03 \pm 5.46$ and $50.94 \pm 4.65$ respectively). The mean decrease in $\mathrm{Km}$ was $2.7 \mathrm{D}$.

The mean decrease in the $\mathrm{K}$ mean was better in our study (3-5) D Vs (2.7) D in this study. That could be explained that Also using the same device but with different surgical technique.

Our results after we change the site of insertion in 9 cases after 3 months from the flat axis to tradional site (steep meridian)axis. UCVA after 6 months improved in $90 \%$ of patients $50 \%$ gained more than 2 lines, $30 \%$ Gained 2 lines, 10\% Gained 1 line, 10\% showed no improvement. None patients were worsened at this group \& BCVA was improved in $93.3 \%$ of patients,30\% gained more than 2 lines, 53.3\% Gained 2 lines and 10\%patients Gained 1 line, 6.6\% showed no improvement. None patients were worsened at this group of patients

These results agree with [20] also using the same device (kera Ring)but with surgical technique As regard improvement in

UCVA, there was no change in 3 cases (12.0\%),improvement in 21 cases $(84.0 \%)$ and deteriorated in one case $(4.0 \%)$. In addition, as regard to improvement in BCVA, there was improvement in 24 cases $(96.0 \%)$ and deterioration in in one case $(4.0 \%)$.

These results in agree with [21] At the 6-month follow-up examination, the mean UCVA increased from $0.10 \pm 0.11$ to $0.32 \pm 0.25(\mathrm{P}, 0.05)$, The mean BSCVA increased from $0.36 \pm 0.23$ to $0.57 \pm 0.24$ (P, $0.05)$. The BSCVA remained at the preoperative level in $(7.3 \%)$ and increased in $(87.3 \%)$. Of these, 31eyes $(56.4 \%)$ gained 2 to 4 lines of VA and $(5.5 \%)$ gained 5 to 8 lines of VA., (5.5\%) had a 1-line decrease in BSCVA.

But disagree with [14] who compare insertion of Intacs by femto vs mechanical surgery, UCVA improved in both groups at 6 months $(P, 0.02)$ and BSCVA improved in the Femtosecond group and not improved in in the Mechanical group ( $\left.r_{-} 0.63, P \_0.04\right)$.

That could be explained that Also using the same device but with different surgical technique there were no improvement in the mechanical group.

These results disagree with [9] By 6 months after ICRS implantation, $12.5 \%$ of patients had lost 1 line, $22.5 \%$ had no change, $22.5 \%$ of eyes gained 1 line, $22.5 \%$ eyes gained 2 lines, and $20 \%$ eyes gained more than 2 Lines.

That could be explained that Also using the same device but with different mechanical technique, different type of patients with different degree of keratoconus.

\section{Conclussion}

Insertion of intra corneal segments in the steep axis is better than flat axis

\section{References}

[1] J.H. Krachmer, R.S. Feder, Non inflammatory corneal thinning disorders. American Academy of Ophthalmology Cornea/External Disease Panel.Preferred Practice PatternR Guidelines. Corneal Ectasia. San Francisco,CA: American Academy of Ophthalmolog,2013.

[2] Belin, Villavicencio, Ambrosio,Tomographic parameters for the detection of keratoconus: suggestions for screening and treatment parameters. Eye Contact Lens, Vol.40, PP.326330,2014.

[3] R.A. Applegate, E.J. Sarver, Are all aberrations equal? J Refract Surg 2012, Vol. 18, PP.S556S562m,2012.

[4] Pena-Garcia, Alio, Vega-Estrada, Internal, corneal, and refractive astigmatism as prognostic factors for intrastromal corneal ring segment implantation in mild to moderate keratoconus. J Cataract Refract Surg, Vol.40, PP.16331644,2014.

[5] A. Vegaestrada, J.L. Alio, The use of intracorneal 
ring segments in keratoconus. Eye Vis (Lond), Vol.3(1), PP.8,2016.

[6] K.G. Carrasquillo, J. Rand, Intacs for keratoconus and post-LASIK ectasia: mechanical versus femtosecond laser-assisted channel creation. Cornea, Vol.26(8), PP.956-962,2007.

[7] A. Daxer ,Biomechanics of corneal ring implants. Cornea, Vol.34(1), PP. 1493-1498,2015.

[8] R.Shetty, S.D’Souza, Ramachandran, Decision making nomogram for intrastromal corneal ring segments in keratoconus. Indian J Ophthalmol, Vol.62, PP.23-28,2014.

[9] M.D. Jos Alfonso, Carlos Lisa, Intrastromal corneal ring segments and posterior chamber phakic intraocular lens implantation for keratoconus correction Cataract Refract Surg, Vol.37, PP.706-713,2011.

[10] Alfredo Vega, Estrada, Jorge,outcome analysis of ICRS for the treatment of keratoconus based on visual, refractive, and aberrometric impairment(am jophthalmol, Vol.155, PP.575584) ,2013.

[11] Ana Carolina, Luisa Malheiro etal , Implantation of ICRS in pediatric patients: long-term follow-up International Medical Case Reports Journal, PP. 23-27,2018.

[12] L.Jorge, Alfredo Vega, Intrastromal Corneal Ring Segments: How Successful is the Surgical Treatment of Keratoconus. Middle East African Journal of Ophthalmology, Volume, Vol. 21, IP, PP. 156.210.178.214,2018.

[13] Pablo Pe na-Garc,Alfredo Vega,Intracorneal Ring Segment in Keratoconus: A Model to Predict Visual Changes Induced by the Surgery IOVS, Vol. 53, No, PP. 13,2018.

[14] P. David, Piñero, Refractive and Aberrometric
Out comes of ICRS for Keratoconus :Mechanical Vs Femtosecond assisted ProcedurOphthalmology, Vol.116, PP.16751687, 2009.

[15] Pinero, Alio, Teus, Modeling the Intracorneal Ring Segment Effect in Keratoconus Using Refractive, Keratometric, and Corneal Aberrometric Data. IOVS , Vol. 51(11), PP.5583-5591,2010.

[16] Ertan, Ozkilic , Intracorneal rings for keratoconus and keratectasia. J Cataract Refract Surg, Vol. 33, PP.1303-14,2017.

[17] El Araby Abd El Ghany, Magdy Ezzat Khallaf, evaluation of intracorneal ferrara ring segments in management of keratoconus AAMJ, Vol. 13, PP. NO 4,2015.

[18] Khosrow Jadidi,Seyed Aliasghar, ICRS Implanation (Keraring) in Patients with CentralKeratoconus:6-Month Follow-Up Journal of OphthalmologyVolume 2015, Article ID, PP. 916385, 8 pages, 2015 .

[19] M.D. Leonardo, Rodrigo Fabri Berbel, Long-term follow-up of intrastromal corneal ring segments in keratoconus, 2009.

[20] Aly mohamed, adel abdel razek , intrastromal corneal keraring segments for keratoconus ophthalmology department of zagazig university hospital z.u.m.j, Vol. 20, PP. n.3,2014.

[21] M. Almutez, B.MDIlham AbuKhader, KeraRing Intrastromal Corneal Ring Segments for Correction of Keratoconus Department of Ophthalmology, Faculty of Medicine, The University of Jordan and Jordan University Hospital, POBox 13046, Amman 11942, Jordan (e-mail: a.gharaibeh@ju.edu.jo),2011. 